\title{
Cytotoxic Bromoindole Derivatives and Terpenes from the Philippine Marine Sponge Smenospongia sp.
}

Deniz Tasdemir*,a,b, Timothy S. Bugnia ${ }^{\mathrm{a}}$, Gina C. Mangalindan ${ }^{\mathrm{c}}$, Gisela P. Concep-

ción $^{\mathrm{c}}$, Mary Kay Harper ${ }^{\mathrm{a}}$ and Chris M. Ireland ${ }^{\mathrm{a}}$

a Department of Medicinal Chemistry, College of Pharmacy, University of Utah,

Salt Lake City, Utah 84112, U.S. A.

b Department of Pharmacognosy, Faculty of Pharmacy, Hacettepe University,

TR-06100 Ankara, Turkey. Fax: +90-312-3114777. E-mail: dtasdemi@hacettepe.edu.tr

c Marine Science Institute, University of the Philippines, Diliman, Quezon City 1101, Philippines

* Author for correspondence and reprint requests

Z. Naturforsch. 57c, 914-922 (2002); received March 21/May 16, 2002

Smenospongia, Bromoindole Derivatives, Pyrroloiminoquinone Alkaloid

A detailed chemical analysis of a Philippine marine sponge Smenospongia sp. has been performed. This study yielded four new metabolites, 5-bromo-L-tryptophan (1), 5-bromoabrine (2), 5,6-dibromoabrine (3) and 5-bromoindole-3-acetic acid (4). The pyrroloiminoquinone alkaloid, makaluvamine $\mathrm{O}(5)$ as well as 5,6-dibromotryptamine (6), aureol (7) and furospinulosin 1 (8) were also isolated. Although $\mathbf{1}$ and $\mathbf{4}$ have been synthesized previously, this is the first report on the isolation of these compounds from a natural source. The furanosesterterpene furospinulosin $1(\mathbf{8})$ was obtained for the first time from the genus Smenospongia. The structures of all compounds were established by spectroscopic methods (UV, IR, $1 \mathrm{D}$ and $2 \mathrm{D}$ NMR, MS, $\left.[\alpha]_{\mathrm{D}}\right)$. The cytotoxic potential of $\mathbf{1 - 8}$ was evaluated in a panel of isogenic HCT-116 human colon tumor cell lines.

\section{Introduction}

Many brominated indole derivatives have been isolated from marine sources and shown to exhibit interesting biological activities (Davidson, 1993; Gribble 1992). In the continuation of our investigations into the chemistry of marine organisms, we investigated a Smenospongia sp. collected from the Philippines. Detailed examination of this sponge has resulted in the isolation of a variety of simple indole alkaloids, 5-bromo-L-tryptophan (1), 5-bromoabrine (5-bromo-N-methyl-L-tryptophan, 2), 5,6-dibromoabrine (5-bromo-N-methyl-L-tryptophan, 3) and 5-bromoindole-3-acetic acid (4). The pyrroloiminoquinone alkaloid makaluvamine O (5), as well as 5,6-dibromotryptamine (6), aureol (7) and furospinulosin 1 (8) were also isolated and characterized. In this paper, we describe the isolation and the structure elucidation of $\mathbf{1 - 4}$. The cytotoxic activity of all compounds (1-8) will also be presented.

\section{Experimental}

General experimental procedures

UV spectra were recorded in $\mathrm{MeOH}$ on a Hewlett-Packard 8452A diode array spectrophotometer. IR spectra were recorded using a Jasco FTIR420 spectrophotometer $(\mathrm{NaCl}$ disk). Optical rotations were measured on a Jasco DIP-370 Digital Polarimeter $(589 \mathrm{~nm})$. NMR spectra were acquired at $26{ }^{\circ} \mathrm{C}$ on a Varian $400 \mathrm{MHz}$ instrument. Mass spectra were taken on Finnigan MAT 95 (FABMS) and Finnigan LCQ DECA ion trap (ESIMS) spectrometers. Prediction of EIMS fragmentation patterns was made by High Chem Mass Frontier program (version 2.0). HPLC separations were performed on a Varian C-18 semi-preparative column $(250 \times 10 \mathrm{~mm}$ i. $\mathrm{d}, 4 \mathrm{ml} / \mathrm{min})$ using a Beckman 168 photodiode array system (202 nm). For flash chromatography, $\mathrm{SiO}_{2}$ (Merck Kieselgel 60, particle size $0.040-0.063 \mathrm{~mm}$ ) and C-18 material (J. T. Baker, $40 \mu \mathrm{m}, 275 \AA$ A) were used. Sephadex LH-20 and D-tryptophan were purchased from Sigma while 5-bromoindole-3-acetic acid was purchased from Aldrich. 


\section{Animal material}

The specimen of Smenospongia sp. was collected by SCUBA in Batanes, Philippines, in 1999 and kept frozen until the work-up. The sponge was identified by one of us (M. K. H.). Voucher specimens (\# PBat99-3-56) were deposited at both the University of the Philippines and the University of Utah.

\section{Extraction and isolation}

Thawed sponge material was soaked in $\mathrm{MeOH}$ $(250 \mathrm{ml})$ for $24 \mathrm{~h}$ and the solution was decanted. This procedure was repeated three times. The combined $\mathrm{MeOH}$ extracts $(1.59 \mathrm{~g})$ were evaporated to dryness in vacuo to give a brown residue, which was dissolved in $10 \% \mathrm{H}_{2} \mathrm{O}$ in $\mathrm{MeOH}(200 \mathrm{ml})$ and partitioned against hexane $(3 \times 200 \mathrm{ml})$. The water content of the $\mathrm{MeOH}$ phase was then adjusted to $30 \%$ by adding $80 \mathrm{ml}$ water before partitioning against $\mathrm{CHCl}_{3}$. The hexane extract $(291 \mathrm{mg})$ was concentrated and passed through a flash silica column using a hexane: EtOAc gradient. The fraction eluted with $20 \%$ EtOAc in hexanes was purified by $\mathrm{C}-18$ HPLC using an isocratic $\mathrm{MeCN}-\mathrm{H}_{2} \mathrm{O}$ $(98: 2, \mathrm{v} / \mathrm{v})$ mixture to yield furospinulosin 1 (8, $8.0 \mathrm{mg}$ ). The fraction eluted with $30 \%$ EtOAc in hexane was pure aureol $(\mathbf{7}, 35.0 \mathrm{mg})$.

The $\mathrm{CHCl}_{3}$ extract $(254.0 \mathrm{mg})$ was fractionated by $\mathrm{C}-18$ FCC using $\mathrm{MeOH}$ gradients in $\mathrm{H}_{2} \mathrm{O}$. The fractions eluted with 30,50 and $100 \%$ of $\mathrm{MeOH}$ in $\mathrm{H}_{2} \mathrm{O}$ afforded 5-bromoindole-3-acetic acid (4, $2.2 \mathrm{mg})$, makaluvamine $\mathrm{O}(\mathbf{5}, 3.0 \mathrm{mg})$, and 5,6-dibromotryptamine $(6,51.8 \mathrm{mg})$, respectively.

The aqueous $\mathrm{MeOH}$ layer was repeatedly triturated with $\mathrm{MeOH}$ to remove insoluble salts before applying to a C-18 flash column. Employment of a multistep $\mathrm{MeOH}$ gradient $(0-100 \% \mathrm{MeOH})$ in $\mathrm{H}_{2} \mathrm{O}$ gave 11 fractions. The fractions eluted with 40 and $50 \% \mathrm{MeOH}$ in water were combined. During the evaporation of this fraction, a precipitate formed, which was identified as 5-bromo-L-tryptophan (1, $20.0 \mathrm{mg})$. The $\mathrm{MeOH}$-soluble portion was purified over Sephadex LH-20 using 70\% $\mathrm{MeOH}$ in water as eluent. 5-bromoabrine (2) was isolated as a light brown powder $(2.2 \mathrm{mg})$. During the concentration of the combined C-18 flash CC fractions eluted with 60 and $70 \% \mathrm{MeOH}$, another precipitate formed. After filtration and rinsing
$(\mathrm{MeOH})$, the residue was dried and identified as 5,6-dibromoabrine $(\mathbf{3}, 10 \mathrm{mg})$.

5-Bromo-L-tryptophan (1): Brownish amorphous powder. $[\alpha]_{\mathrm{D}}^{22}=-24^{\circ}(c=0.05, \mathrm{MeOH})$. UV (MeOH): 230 (3.87), 290 (3.47). IR ( NaCl): 3446, 3408, 3005, 1654, 1577. ${ }^{1} \mathrm{H}$ NMR (400 MHz, DMSO- $d_{6}$ ) Table I; ${ }^{13} \mathrm{C}$ NMR $(100 \mathrm{MHz}$, DMSO$\left.d_{6}\right)$ Table II. HREIMS $207.9769\left(\left[\mathrm{M}-\mathrm{C}_{2} \mathrm{H}_{4} \mathrm{NO}_{2}\right]^{+}\right.$, $\mathrm{C}_{9} \mathrm{H}_{7} \mathrm{NBr}^{+}$; calc. 207.9762). EIMS 210 (100, $\left.\left[\mathrm{M}-\mathrm{C}_{2} \mathrm{H}_{4} \mathrm{NO}_{2}\right]^{+}\right), 208\left(95,\left[\mathrm{M}-\mathrm{C}_{2} \mathrm{H}_{4} \mathrm{NO}_{2}\right]^{+}\right), 195$ (20), 197 (20), 129 (31), 44 (52). (-)-ESIMS 283 $[\mathrm{M}-\mathrm{H}]^{-}, 281[\mathrm{M}-\mathrm{H}]^{-} ;(+)-$ESIMS $285[\mathrm{M}+\mathrm{H}]^{+}$, $283[\mathrm{M}+\mathrm{H}]^{+}, 268\left[\mathrm{M}-\mathrm{NH}_{3}\right]^{+}, 266\left[\mathrm{M}-\mathrm{NH}_{3}\right]^{+}$.

5-Bromoabrine (2): Light brown powder. $[\alpha]_{\mathrm{D}}^{22}=-34^{\circ}(c=0.05, \mathrm{MeOH}),[\alpha]_{\mathrm{D}}^{22}=+45.8^{\circ}$ $(c=0.05,1 \mathrm{~N} \mathrm{HCl}),[\alpha]_{\mathrm{D}}^{22}=+46.0^{\circ}(c=0.05,1 \mathrm{~N}$ $\mathrm{NaOH})$. UV (MeOH): 228 (3.59), 288 (2.92). IR (NaCl): 3234, 2921, 1622, 1394. ${ }^{1} \mathrm{H} \quad \mathrm{NMR}$ (400 MHz, DMSO- $d_{6}$ ) Table I; ${ }^{13} \mathrm{C}$ NMR (100 MHz, DMSO- $d_{6}$ ) Table II. HREIMS 209.9731 ([M$\left.\mathrm{C}_{3} \mathrm{H}_{6} \mathrm{NO}_{2}\right]^{+}, \mathrm{C}_{9} \mathrm{H}_{7}{ }^{81} \mathrm{BrN}^{+}$, calc. 209.9741), 207.9750 ([M-C $\left.\mathrm{M}_{3} \mathrm{H}_{6} \mathrm{NO}_{2}\right]^{+}, \mathrm{C}_{9} \mathrm{H}_{7}{ }^{79} \mathrm{BrN}^{+}$, calc. 207.9762). EIMS $298\left(<1,[\mathrm{M}]^{+}\right), 296\left(<1,[\mathrm{M}]^{+}\right), 208(100$, $\left.\left[\mathrm{M}-\mathrm{C}_{3} \mathrm{H}_{6} \mathrm{NO}_{2}\right]^{+}\right), \quad 210 \quad\left(100, \quad\left[\mathrm{M}-\mathrm{C}_{3} \mathrm{H}_{6} \mathrm{NO}_{2}\right]^{+}\right)$. (+)-ESIMS $299[\mathrm{M}+\mathrm{H}]^{+}, 297[\mathrm{M}+\mathrm{H}]^{+}$.

5,6-Dibromoabrine (3): Light brown powder. $[\alpha]_{\mathrm{D}}^{22}=-31^{\circ}(c=0.4, \mathrm{MeOH}),[\alpha]_{\mathrm{D}}^{22}=+43.5^{\circ}$ $(c=0.05,1 \mathrm{~N} \mathrm{HCl}),[\alpha]_{\mathrm{D}}^{22}=+44.0^{\circ}(c=0.05,1 \mathrm{~N}$ $\mathrm{NaOH})$. UV (MeOH): 228 (3.69), 290 (2.97). IR (NaCl): 3448, 3408, 3011, 1660, 1582. ${ }^{1} \mathrm{H}$ NMR $\left(400 \mathrm{MHz}\right.$, DMSO- $\left.d_{6}\right)$ Table I; ${ }^{13} \mathrm{C}$ NMR $\left(100 \mathrm{MHz}\right.$, DMSO- $\left.d_{6}\right)$ Table II. HREIMS $285.8847\left(\left[\mathrm{M}-\mathrm{C}_{3} \mathrm{H}_{6} \mathrm{NO}_{2}\right]^{+}, \quad \mathrm{C}_{9} \mathrm{H}_{6}{ }^{79} \mathrm{Br}_{2} \mathrm{~N}^{+}\right.$, calc. 285.8867). EIMS 290 (3), 288 (6), 286 (3) (all [M$\left.\mathrm{C}_{3} \mathrm{H}_{6} \mathrm{NO}_{2}\right]^{+}$). (+)-ESIMS 379, 377, 375 (all $\left.[\mathrm{M}+\mathrm{H}]^{+}\right), 348,346,344\left(\right.$ all $\left[\mathrm{M}-\mathrm{CH}_{3} \mathrm{NH}_{2}\right]^{+}$).

5-Bromoindole-3-acetic acid (4): Brownish amorphous powder. ${ }^{1} \mathrm{H}$ NMR (400 MHz, DMSO$\left.d_{6}\right)$ Table I; ${ }^{13} \mathrm{C}$ NMR (100 MHz, DMSO- $\left.d_{6}\right)$ Table II. HREIMS $252.9757 \quad\left(\mathrm{C}_{10} \mathrm{H}_{8} \mathrm{NO}_{2}{ }^{79} \mathrm{Br}^{+}\right.$, calc. 252.9738). EIMS $255\left(48,[\mathrm{M}]^{+}\right), 253$ (48, $\left.[\mathrm{M}]^{+}\right), 210(100), 208$ (100), 145 (32), 129 (36), 81 (61), 69 (84).

Makaluvamine O (5). Purple solid. UV (MeOH): 222 (3.81), 244 (3.28), 328 (2.94), 362 (sh, 2.86), 542 (2.06). IR ( NaCl): 3398, 3002, 2916, 1653. ${ }^{1} \mathrm{H}$ NMR (400 MHz, DMSO- $d_{6}$ ) Table I; ${ }^{13} \mathrm{C}$ NMR (100 MHz, DMSO- $\left.d_{6}\right)$ Table II. HREIMS $265.9691\left([\mathrm{M}]^{+}, \mathrm{C}_{10} \mathrm{H}_{7}{ }^{79} \mathrm{BrN}_{2} \mathrm{O}_{2}{ }^{+}\right.$, calc. 265.9697); EIMS $268\left(<1,\left([\mathrm{M}]^{+}\right), 266\left(<1,\left([\mathrm{M}]^{+}\right), 165(2)\right.\right.$, 
103 (3), 91 (100). (+)-ESIMS $269[\mathrm{M}+\mathrm{H}]^{+}, 267$ $[\mathrm{M}+\mathrm{H}]^{+}$.

HCT-116 cell lines. The $\mathrm{p} 53^{-/-}, \mathrm{p} 53^{+/+}, \mathrm{p} 21^{-/-}$, and $\mathrm{p} 21^{+/+}$isogenic cell lines were obtained from Dr. Bert Vogelstein at Johns Hopkins University (U.S.A). All cell culture reagents were purchased from $G I B C O$ with the exception of the antibiotic/ antimycotic (Sigma). The HCT cells were cultured in McCoy's 5A medium containing $10 \%$ fetal bovine serum, $1.0 \mathrm{~mm}$ sodium pyruvate, $2.0 \mathrm{~mm} \mathrm{L-glu-}$ tamine, 40 units $/ \mathrm{ml}$ penicillin, $40 \mu \mathrm{g} / \mathrm{ml}$ streptomycin, and $0.1 \mu \mathrm{g} / \mathrm{ml}$ amphotericin B. Cultures were incubated at $37^{\circ} \mathrm{C}$ in a $5 \% \mathrm{CO}_{2}$ atmosphere. Cells were washed with 2 ml EDTA (sodium) in phosphate buffered saline (Versene, 1:5000) and harvested in $3 \mathrm{ml}$ of a $0.25 \%$ trypsin $0.03 \%$ EDTA solution. The trypsin was quenched by the addition of $12 \mathrm{ml}$ of culture medium, and the cells pelleted by centrifugation for five min at room temperature. The pellet was resuspended in $15 \mathrm{ml}$ of fresh medium and the cell concentration was determined using a Coulter counter. Cells were seeded in 96-well plates (3000 cells/well) in $200 \mu \mathrm{l}$ of medium and allowed to adhere for $24 \mathrm{~h}$. The medium was aspirated and replaced with $180 \mu \mathrm{l}$ of fresh medium. Cells were treated with a $20 \mu \mathrm{l}$ solution of compound dissolved in $10 \%$ DMSO in

PBS. Plates were subsequently incubated for $72 \mathrm{~h}$, the media aspirated, and $100 \mu \mathrm{l}$ of fresh medium was added. $11 \mu \mathrm{l}$ of $2.5 \mathrm{mg} / \mathrm{ml}$ MTT (3,[4,5-dimethylthiazol-2-yl]-2,5-diphenyltetrazolium bromide) was added to assess cell viability. Plates were incubated with MTT for 4 hours, the media was aspirated, and $100 \mu \mathrm{l}$ of DMSO was added to each well. Plates were shaken to dissolve the reduced MTT and the absorbance was measured at $570 \mathrm{~nm}$ using a Multiskan Plus 96-well plate reader. The percent survival in each well was determined by dividing the absorbance of the test well by the average absorbance in wells treated only with DMSO. All samples were tested in quadruplicate.

\section{Results and Discussion}

The Smenospongia sp. was collected from Batanes (Philippines) in 1999 and stored frozen until processed. The thawed animal was extracted with $\mathrm{MeOH}$. The crude $\mathrm{MeOH}$ extract was submitted to our standard solvent-solvent extraction protocol (see Experimental) and yielded hexane, $\mathrm{CHCl}_{3}$ and aqueous $\mathrm{MeOH}$-solubles. Each extract was individually chromatographed by a combination of C-18/silica flash column chromatography (FCC), silica HPLC and Sephadex LH-20 to give 1-8 (Fig. 1).

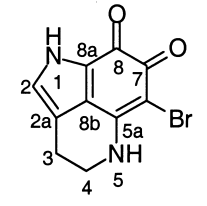

5

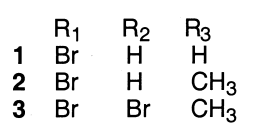

(N)

6

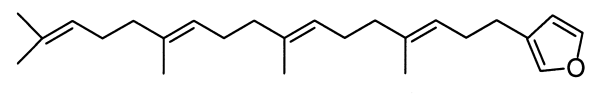

8
Fig. 1. Bromoindole derivatives (16) and terpenes $(\mathbf{7}, \mathbf{8})$ from the Smenospongia sp. 
<smiles>[R]c1cc2c([R6])cc3[nH]cc(CC(N)C(=O)O)c3c2cc1[R]</smiles>

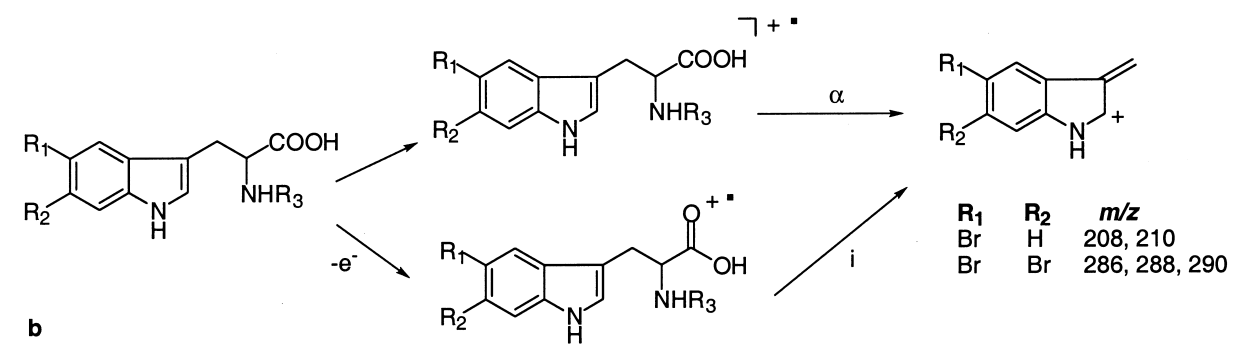

Fig. 2. EIMS fragmentation patterns proposed for bromoindole derivatives, 1-4 $(\alpha=\alpha$ cleavage, $i=$ inductive charge transfer $)$

5-bromo-L-tryptophan (1) was isolated as a brownish amorphous powder. Although 1 was previously synthesized (Irie et al., 1984), it was obtained as a natural product in the present investigation. Compound $\mathbf{1}$ has been produced as a diet metabolite from corresponding indole derivative and serine, catalyzed by Achromobacter petrophilum (Kitajima et al., 1973). The negative and positive ESIMS of 1 gave pseudomolecular ion peaks at $m / z 281,283\left([\mathrm{M}-\mathrm{H}]^{-}\right)$; and $m / z 283,285$ $\left([\mathrm{M}+\mathrm{H}]^{+}\right)$, respectively, in a ratio of $1: 1$. This was indicative of a bromine atom in the molecule. The EIMS of 1 also contained prominent peaks of nearly equal intensity at $\mathrm{m} / z 207.9769$ and 210 . The loss of $m / z 74\left(\mathrm{C}_{2} \mathrm{H}_{4} \mathrm{NO}_{2}\right)$ from the even $[\mathrm{M}]^{+}$was compatible with the presence of a $\mathrm{NH}_{2} \mathrm{CHCOOH}$ terminus (Fig. 2). This data, combined with the ${ }^{13} \mathrm{C}$ NMR resonances shown in Table II, fixed the molecular formula as $\mathrm{C}_{11} \mathrm{H}_{11} \mathrm{BrN}_{2} \mathrm{O}_{2}$. The UV spectrum showed the characteristic indole chromophore with absorptions at 230 and $290 \mathrm{~nm}$. The ${ }^{1} \mathrm{H}$ NMR spectrum of 1 in DMSO- $d_{6}$ (Table I) contained four aromatic $\mathrm{sp}^{2}$ protons; a diastereotopic methylene, a methine and a downfield $\mathrm{D}_{2} \mathrm{O}$-exchangeable proton ( $\delta$ 11.20), which is diagnostic for the NH proton of the indole ring. The gradient COSY
Table II. ${ }^{13} \mathrm{C}$ NMR data of $\mathbf{1 - 5}$ (DMSO- $d_{6}, 100 \mathrm{MHz}$ ), $\delta$ in $\mathrm{ppm}$

\begin{tabular}{cccccc}
\hline${ }^{13} \mathrm{C}$ & $\mathbf{1}$ & $\mathbf{2}$ & $\mathbf{3}$ & $\mathbf{4}$ & $\mathbf{5}$ \\
\hline 2 & $125.9 \mathrm{~d}$ & $125.9 \mathrm{~d}$ & $127.0 \mathrm{~d}$ & $125.5 \mathrm{~d}$ & $124.9 \mathrm{~d}$ \\
$2 \mathrm{a}$ & & & & & $123.7 \mathrm{~s}$ \\
3 & $109.4 \mathrm{~s}$ & $109.0 \mathrm{~s}$ & $109.1 \mathrm{~s}$ & $108.3 \mathrm{~s}$ & $19.1 \mathrm{t}$ \\
4 & $120.8 \mathrm{~d}$ & $121.1 \mathrm{~d}$ & $123.4 \mathrm{~d}$ & $121.1 \mathrm{~d}$ & $42.2 \mathrm{t}$ \\
5 & $110.9 \mathrm{~s}$ & $111.0 \mathrm{~s}$ & $114.8 \mathrm{~s}$ & $110.9 \mathrm{~s}$ & \\
$5 \mathrm{a}$ & & & & & $150.9 \mathrm{~s}$ \\
6 & $123.2 \mathrm{~d}$ & $123.3 \mathrm{~d}$ & $112.6 \mathrm{~s}$ & $123.3 \mathrm{~d}$ & $87.4 \mathrm{~s}$ \\
7 & $113.3 \mathrm{~d}$ & $113.2 \mathrm{~d}$ & $115.9 \mathrm{~d}$ & $113.3 \mathrm{~d}$ & $168.3 \mathrm{~s}$ \\
8 & $135.0 \mathrm{~s}$ & $134.9 \mathrm{~s}$ & $136.0 \mathrm{~s}$ & $134.8 \mathrm{~s}$ & $172.1 \mathrm{~s}$ \\
$8 \mathrm{a}$ & & & & & $124.5 \mathrm{~s}$ \\
$8 \mathrm{~b}$ & & & & & $117.5 \mathrm{~s}$ \\
9 & $129.3 \mathrm{~s}$ & $129.3 \mathrm{~s}$ & $128.6 \mathrm{~s}$ & $129.2 \mathrm{~s}$ & \\
10 & $26.8 \mathrm{t}$ & $25.7 \mathrm{t}$ & $25.5 \mathrm{t}$ & $30.9 \mathrm{t}$ & \\
11 & $54.7 \mathrm{~d}$ & $63.3 \mathrm{~d}$ & $63.2 \mathrm{~d}$ & $172.5 \mathrm{~s}$ & \\
12 & $170.0 \mathrm{~s}$ & $169.0 \mathrm{~s}$ & $168.9 \mathrm{~s}$ & & \\
$13(\mathrm{~N}-\mathrm{Me})$ & & $32.3 \mathrm{q}$ & $32.2 \mathrm{q}$ & & \\
\hline
\end{tabular}

spectrum of $\mathbf{1}$ revealed three spin-coupled networks. The isolated aromatic proton at $\delta 7.26$, which is typical of the H-2 of a 3-substituted indole (Thymiak et al., 1985), showed a weak coupling $(J=2.0 \mathrm{~Hz})$ with the NH proton. The other two aromatic proton signals at $\delta 7.14$ and 7.31 constituted a vicinal pair, which could be assigned as two ortho-positioned protons, $\mathrm{H}-6$ and $\mathrm{H}-7$, respectively, from their homonuclear coupling constants 
Table I. ${ }^{1} \mathrm{H}$ NMR data of $\mathbf{1}-\mathbf{5}$ (DMSO- $\left.d_{6}, 400 \mathrm{MHz}\right) . \delta$ in ppm, $J$ in $\mathrm{Hz}$

\begin{tabular}{|c|c|c|c|c|c|c|}
\hline${ }^{1} \mathrm{H}$ & 1 & $\begin{array}{l}\text { HMBCs of } 1 \\
\text { H to C }\end{array}$ & 2 & 3 & 4 & 5 \\
\hline 2 & $7.26(\mathrm{~d}, 2.0)$ & $3,8,9$ & $7.26(\mathrm{~d}, 2.0)$ & $7.31(\mathrm{~s})$ & 7.25 (br s) & $7.14 \mathrm{~s}$ \\
\hline 4 & $7.74(\mathrm{~d}, 2.0)$ & $3,5,6,8$ & $7.77(\mathrm{~d}, 2.0)$ & $8.02(\mathrm{~s})$ & $7.66(\mathrm{~d}, 2.0)$ & $3.60(\mathrm{t}, 7.3)$ \\
\hline 6 & $7.14(\mathrm{dd}, 2.0,8.6)$ & $4,5,8$ & $7.15(\mathrm{dd}, 2.0,8.6)$ & & $7.15(\mathrm{dd}, 2.0,8.6)$ & \\
\hline 7 & $7.31(\mathrm{~d}, 8.6)$ & 5,9 & $7.29(\mathrm{~d}, 8.6)$ & $7.73(\mathrm{~s})$ & $7.29(\mathrm{~d}, 8.6)$ & \\
\hline 11 & $3.50(\mathrm{dd}, 4.3,7.8)$ & $3,10,12$ & $3.35(\mathrm{dd}, 5.5,11.3)$ & $3.38(\mathrm{dd}, 5.1,10.9)$ & & \\
\hline 13 & & & $2.38 \mathrm{~s}$ & $2.41 \mathrm{~s}$ & & \\
\hline \multicolumn{7}{|l|}{ (N-Me) } \\
\hline Exch. & $11.20 \mathrm{~s}$ & $2,3,8,9$ & $11.11 \mathrm{~s}$ & $11.22 \mathrm{~s}$ & $11.10 \mathrm{~s}$ & \\
\hline
\end{tabular}

$\left(J_{\mathrm{HH}}=8.6 \mathrm{~Hz}\right) . \mathrm{H}-6$ in turn showed meta coupling with $\mathrm{H}-4(\delta 7.74 \mathrm{~d}, J=2.0 \mathrm{~Hz})$, pointing to a $1,3,4-$ substitution on the benzene ring of the indole. These chemical shifts and the splitting pattern of the aromatic protons indicated the presence of a 5-bromo-3-substituted indole fragment (Thymiak et al., 1985; Djura et al., 1980). This interpretation was supported by an HMBC experiment optimized for $8.0 \mathrm{~Hz}$. All possible ${ }^{3} J_{\mathrm{CH}}$ and some ${ }^{2} J_{\mathrm{CH}}$ correlations were observed (Table I) to favor 5-bromo substition over 6-bromination. The NOE correlation observed between $\mathrm{H}-7$ and the exchangeable NH proton further confirmed the position of the bromine at C-5. The last spin system was assigned to the side chain protons, the diastereotopic methylene ( $\delta 3.03$, dd, $J=7.8,14.8 \mathrm{~Hz}, \mathrm{H}_{2^{-}}$ $10 \mathrm{a} ; 3.24$, dd, $\left.J=4.3,14.8 \mathrm{~Hz}, \mathrm{H}_{2}-10 \mathrm{~b}\right)$ and the methine proton ( $\delta 3.50$, dd, $J=4.3,7.8 \mathrm{~Hz}, \mathrm{H}-11$ ). Analysis of the HMQC spectrum indicated that the latter proton was attached to a carbon $(\delta 54.7$ d, C-11) $\alpha$ to a nitrogen group, probably an $\mathrm{NH}_{2}$. $\mathrm{H}-11$ showed two bond couplings with both $\mathrm{C}-10$ ( $\delta$ 26.8) and C-12 ( $\delta$ 170.0). The connection between the side chain (through C-10) and the indole ring (C-3) ring was readily established by the key HMBC correlations shown on Table I, thereby completing the planar structure of $\mathbf{1}$. The $S$ stereochemistry at C-11 was determined by comparison of the specific rotation value of $\mathbf{1}\left([\alpha]_{\mathrm{D}}{ }^{22}=-24.0^{\circ}\right)$ with that of D-tryptophan $\left([\alpha]_{\mathrm{D}}{ }^{22}=+41.6^{\circ}, c=0.5\right.$, Sigma) in $\mathrm{MeOH}$. The chemical shifts and the coupling constants observed for the side chain protons and carbons further supported that $\mathbf{1}$ was a $\alpha$-amino acid derivative. Thus, 1 was identified as 5-bromo-L-tryptophan.
5-Bromoabrine (2) was also isolated as a light brown amorphous powder, which showed typical UV and IR absorptions for a tryptophan structure (see Experimental). In the low resolution ESIMS, 2 showed 1:1 doublet molecular ion peaks $[\mathrm{M}+\mathrm{H}]^{+}$ at $m / z 297$ and 299, consistent with the molecular formula $\mathrm{C}_{12} \mathrm{H}_{13} \mathrm{BrN}_{2} \mathrm{O}_{2}$. The NMR data of $\mathbf{2}$ were almost identical with those of $\mathbf{1}$ and were assignable to a disubstituted indole moiety, a methylene, a nitrogenous methine, a downfield $\mathrm{D}_{2} \mathrm{O}$-exchangeable proton and a carboxylic acid (Tables I and II). However, 2 contained an extra singlet at $\delta_{\mathrm{H}} 2.38$ that correlated with a ${ }^{13} \mathrm{C}$ signal at $\delta 32.3$ (q) in the HMQC spectrum. These chemical shift values are very typical for an aliphatic N-methyl (C-13) function. Hence, the N-methyl substitution was predicted to be on the amino group of the side chain, and not on the indole nitrogen. The base peaks observed in the HREIMS at $\mathrm{m} / z, 207.9750$ and 209.9731 corresponded to the molecular formula of $\mathrm{C}_{9} \mathrm{H}_{7}{ }^{79} \mathrm{BrN}$ and $\mathrm{C}_{9} \mathrm{H}_{7}{ }^{81} \mathrm{BrN}$, indicating the loss of $\mathrm{C}_{3} \mathrm{H}_{6} \mathrm{NO}_{2}\left(\mathrm{CHNHCH}_{3} \mathrm{COOH}, 88 \mathrm{amu}\right)$ from $[\mathrm{M}]^{+}$as depicted in Fig. 2. HMBC cross peaks from the N-methyl signal ( $\delta$ 2.38) to C-10 $(\delta$ 25.7) and C-11 ( $\delta$ 63.3) unambigiously confirmed the proposed structure for $\mathbf{2}$. The stereochemistry of the only chiral center (C-11) was assigned $S$ based on the sign of the specific rotation value $\left([\alpha]_{\mathrm{D}}^{22}=-34.0^{\circ}, \mathrm{MeOH}\right)$. Thus, compound 2 was identified as 5-bromo-N-methyl-L-tryptophan. A computer search indicated that the nonbromo derivative, N-methyl-L-tryptophan (= abrine), was previously isolated from several leguminous plants (Cannon and Williams, 1982; Kinjo et al., 1991; Ma et al., 1998). In order to further con- 
firm the stereochemistry of $\mathrm{C}-11$, we remeasured the specific rotation of 2 in both $\mathrm{HCl}$ and $\mathrm{NaOH}$ in which abrine was measured (Cannon and Williams, 1982; Kinjo et al., 1991; Ma et al., 1998). The positive sign observed in each solvent clearly evidenced that $\mathbf{2}$ had the same (L) stereochemistry as abrine $\left[\left(1 \mathrm{~N} \mathrm{HCl}:[\alpha]_{\mathrm{D}}^{22}=+45.8^{\circ}\right.\right.$ for $2,+44.9^{\circ}$ for abrine (Cannon and Williams, 1982); $1 \mathrm{~N} \mathrm{NaOH}$ : $[\alpha]_{\mathrm{D}}^{22}=+46.0^{\circ}$ for $2,+56.1^{\circ}$ for abrine (Ma et al., 1998)].

The positive mode ESIMS of $\mathbf{3}$ showed a molecular ion $\left([\mathrm{M}+\mathrm{H}]^{+}\right)$cluster at $m / z 375\left(\left[\mathrm{C}_{12} \mathrm{H}_{13}{ }^{79}\right.\right.$ $\left.\left.\mathrm{Br}_{2} \mathrm{~N}_{2} \mathrm{O}_{2}\right]^{+}\right), \quad 377\left(\left[\mathrm{C}_{12} \mathrm{H}_{13}{ }^{79} \mathrm{Br}^{81} \mathrm{BrN}_{2} \mathrm{O}_{2}\right]^{+}\right), \quad 379$ $\left(\left[\mathrm{C}_{12} \mathrm{H}_{13}{ }^{81} \mathrm{Br}_{2} \mathrm{~N}_{2} \mathrm{O}_{2}\right]^{+}\right)$in a ratio of $c a 1: 2: 1$, which is in a good agreement with the presence of two bromine atoms. The base peaks in the EIMS of $\mathbf{3}$ $(\mathrm{m} / \mathrm{z}, 286,288$ and 290, 1:2:1) corresponded to loss of $\mathrm{C}_{3} \mathrm{H}_{6} \mathrm{NO}_{2}(88 \mathrm{amu})$ from the $[\mathrm{M}]^{+}$, suggesting that $\mathbf{3}$ possessed the same $\mathrm{N}$-methylated side chain as 2. The NMR data of both the side chain and the indole substructure of $\mathbf{3}$ (Tables I and II) were also very similar to those of $\mathbf{2}$. The major difference originated from the signals of the aromatic region due to the addition of the second bromine atom. The two sharp singlets that emerged at $\delta$ 8.02 and 7.73 were assigned to isolated aromatic protons at $\mathrm{C}-4$ and $\mathrm{C}-7$, which could arise if the bromines were at positions $\mathrm{C}-5$ and $\mathrm{C}-6$. The broad singlet at $\delta 7.31$ that sharpened on exchange $\left(\mathrm{D}_{2} \mathrm{O}\right)$ was due to $\mathrm{H}-2$, thus, the side chain was still attached to $\mathrm{C}-3$. The postulated structure was confirmed by ${ }^{3} J_{\mathrm{CH}}$ and ${ }^{2} J_{\mathrm{CH}}$ HMBC correlations. Of particular help were the pairs $\mathrm{H}-4 / \mathrm{C}-8, \mathrm{H}-4 /$ C-6, H-7/C-5, H-7/C-9, H-4/C-5 and H-7/C-6. The stereochemistry of $\mathrm{C}-11$ was determined on the basis of the specific rotation data $\left([\alpha]_{\mathrm{D}}{ }^{22}=-31^{\circ}\right.$ in $\mathrm{MeOH},[\alpha]_{\mathrm{D}}^{22}=+43.5^{\circ}$ in $1 \mathrm{~N} \mathrm{HCl} ;[\alpha]_{\mathrm{D}}{ }^{22}=$ $+44.0^{\circ}$ in $1 \mathrm{~N} \mathrm{NaOH}$ ). Compound 3 is 5,6-dibromo$\mathrm{N}$-methyl-L-tryptophan for which we propose the trivial name 5,6-dibromoabrine.

Compound 4 was also found to retain the 5bromo-3-substituted-indole substructure, plus a degraded side chain composed of an isolated $\mathrm{CH}_{2}$ $(\delta 3.59 \mathrm{~s}, 2 \mathrm{H})$ and a carboxylic acid $(\delta 172.5)$. From the detailed investigation of $1 \mathrm{D}$ and 2D NMR spectra (Tables I and II) as well as the HREIMS data $(\mathrm{m} / \mathrm{z}, 252.9757$ and 255), compound 4 was identified as 5-bromoindole-3-acetic acid (5-Br-3IAA). This assignment was further confirmed by comparison with the ${ }^{1} \mathrm{H}$ and ${ }^{13} \mathrm{C}$ NMR data of the synthetic standard (Aldrich). 5-Br-3-IAA has been synthesized by Engvild (1977) and we describe its presence in a natural source for the first time.

Compound 5 was obtained as a purple solid. Maxima in the UV spectrum at $\lambda_{\max } 222,244,328$, 362 ( sh) and $542 \mathrm{~nm}$ suggested a pyrroloiminoquinone structure (Radisky et al., 1993). The ${ }^{1} \mathrm{H}$ NMR spectrum (DMSO- $d_{6}$, Table 1 ) of 5 was deceptively simple and contained characteristic pyrroloiminoquinone resonances: an aromatic singlet at $\delta$ 7.14 (H-2) and two mutually coupled methylene signals at $\delta 2.75(\mathrm{H}-3)$ and $3.60(\mathrm{H}-4)$, observed as triplets with $J_{\mathrm{HH}}=7.3 \mathrm{~Hz}$. The ${ }^{13} \mathrm{C}$ and DEPT-135 NMR spectra of $\mathbf{5}$ (Table II) displayed ten carbons. These included two carbonyls whose chemical shifts are indicative of an $o$-quinone group ( $\delta$ 168.3, 172.1), five quaternary carbons, one aromatic $\mathrm{CH}$ and two methylenes. The HREIMS of $5(\mathrm{~m} / \mathrm{z}$ 265.9691 and 267.9) supported the molecular formula $\mathrm{C}_{10} \mathrm{H}_{7} \mathrm{BrN}_{2} \mathrm{O}_{2}$. The NMR data of 5 in fact was quite reminescent of makaluvamine-type pyrroloiminoquinones. Spectroscopic comparisons between 5 and makaluvone, reported by our research group from a Zyzzya sponge (Radisky et al., 1993) suggested both compounds to have a common structural motif, except that 5 lacked the 1-Nmethyl function ( $\delta 3.82$, Radisky et al., 1993) found in makaluvone. Hence, the structure of 5 was established as 1-N-demethylmakaluvone. After the completion of this manuscript, $\mathrm{Hu}$ et al. (2002) have published this compound from the Jamaican Smenospongia aurea, and named makaluvamine $\mathrm{O}$.

The remaining compounds were identified as 5,6-dibromotryptamine (6) (Djura et al., 1980; Van Lear et al., 1973), aureol (7) (Djura et al., 1980) and furospinulosin 1 (8) (Cimino et al., 1972) on the basis of comparison of their NMR, MS and $[\alpha]_{\mathrm{D}}$ data with those reported previously.

All compounds were screened in HCT-116 colon carcinoma cell lines using an MTT assay. Compounds that showed at least moderate cytotoxicity were further examined in a set of isogenic HCT116 cell lines consisting of p53 and p21 knockouts (p53 ${ }^{-/-}$and $\left.\mathrm{p} 21^{-/-}\right)$as well as the parental cell line of each (p53 $3^{+/+}$and $\left.\mathrm{p} 21^{+/+}\right) \cdot \mathrm{p} 53$ is one of the best studied tumor suppressor genes, which primarily functions through its downstream mediator, p21 protein. Since p53 alterations represent the most common mutation found in human tumors, compounds that do not show a p53 dependant 


\begin{tabular}{lcccc}
\hline Compound & $\mathbf{p 5 3}^{+/+}$ & $\mathbf{p 5 3}^{-/-}$ & $\mathbf{p 2 1}^{+/+}$ & $\mathbf{p 2 1}^{-/-}$ \\
\hline 5-Bromo-L-tryptophan (1) & $>177$ & $>177$ & n.t. & n.t. \\
5-Bromoabrine (2) & $>168$ & $>168$ & n.t. & n.t. \\
5,6-Dibromoabrine (3) & $>133$ & $>133$ & n.t. & n.t. \\
5-Bromoindole-3-acetic acid (4) & $>197$ & $>197$ & n.t. & n.t. \\
Makaluvamine O (5) & 71 & 79 & 94 & 8.6 \\
5,6-Dibromotryptamine (6) & 12.6 & 85 & 85 & 63 \\
Aureol (7) & 15.9 & 41 & 73 & 61 \\
Furospinulosin 1 (8) & 105 & 141 & 155 & 133 \\
Etoposide & 3.4 & 17 & 3.4 & 26 \\
\hline
\end{tabular}

Table III. IC I0 $_{50}(\mu \mathrm{M})$ values of $\mathbf{1 - 8}$ in isogenic HCT-116 cell lines.

n.t.: not tested mechanism would be expected to have increased clinical efficacy. Additionally, p21 mutations are also common among human tumors. Identifying compounds with selectivity against genetically defined cell lines may lead to improved therapies.

Makaluvamine O (5), 5,6-dibromotryptamine (6), aureol (7), and furospinulosin 1 (8) all displayed significant activity in HCT-116 cell lines (Table III). With the exception of makaluvamine O (5), all compounds showed decreased activity against the $\mathrm{p} 53^{-/-}$cell line indicative of a p53 dependant mechanism. Makaluvamine $O$ (5) showed a promising activity profile showing very little differential between the p53 cell lines while showing an order of magnitude lower $\mathrm{IC}_{50}(8.6 \mu \mathrm{M})$ against the $\mathrm{p} 21^{-1-}$ cell line.

The genus Smenospongia is well known for producing bromotryptamines (Djura et al., 1980; Van Lear et al., 1973) and aureol-type sesquiterpene phenols (Thymiak et al., 1985; Djura et al., 1980, Bourguet-Kondracki and Guyot, 1989; BourguetKondracki et al., 1992). Although derivatives of aplysinopsin, a tryptophan-derived marine natural product, have also been reported from Smenospongia sp. (Thymiak et al., 1985), we believe this is the first report of bromotryptophans themselves, from this genus. Abrine, N-methyl-L-tryptophan, has been reported from several terrestrial plants (Cannon and Williams, 1982; Kinjo et al., 1991; Ma et al., 1998), but $\mathrm{N}$-methylated tryptophans are being described from a marine sponge, again, for the first time.

3-Indole acetic acid (3-IAA) is a well-known plant growth regulator. Halogenated 3-IAA derivatives including 5-bromoindole-3-acetic acid (4, 5-Br-3-IAA) also show growth promoting activity towards higher plants (Katekar and Geissler, 1983; Rasmussen et al., 1995). Marine algae have yielded several indole type auxins (Bernart and Gerwick,
1990; Bano et al., 1987). The presence of phytohormones in sponges has been suggested to be connected with a symbiotic relation to the algae (Bernart and Gerwick, 1990), although Rasmussen et al. (1993) have reported several 6-bromoindole derivatives with auxin activity from Pseudosuberites hyalinus, collected at a depth of $-405 \mathrm{~m}$. On the other hand, since some bacteria, such as Pseudomonas, have been shown to produce tryptophan derivatives, some with the degraded carbon chain at C-3 (Narumiya et al., 1979), we cannot exclude the possibility that compounds 1-6 originate from a symbiotic organism associated with Smenospongia species. The metabolites 1-6 may also be of dietary origin. Aureol (7), the sesquiterpene hydroquinone, has already been hypothesized to be a dietary metabolite (Thymiak et al., 1985). Furospinulosin 1 (8) is a furanosesterterpene previously isolated from several sponges of the order Dictyoceratida, such as Hippospongia (Nakamura et al., 1986), Ircinia (Cimino et al., 1972), Spongia (Erdogan and Sener, 2001) and Fasciospongia (McPail et al., 1998). This is the first report of $\mathbf{8}$ from a Smenospongia species.

Our investigation on the Philippine Smenospongia species has surprisingly afforded a pyrroloiminoquinone alkaloid, makaluvamine $\mathrm{O}(\mathbf{5})$. This type of compounds are uncommon in nature and have thus far been reported from few sponge genera such as Damiria (Stierle and Faulkner, 1991), Batzella (Sakemi et al., 1989), Prianos (Kobayashi et al., 1987) and Latrunculia (Ford and Capon, 2000). Makaluvamines, specifically, have only been obtained from Zyzzya fuliginosa (order Poecilosclerida) (Radisky et al., 1993; Schmidt et al., 1995; Venables et al., 1997; Tasdemir et al., 2001; Casapullo et al., 2001) and now from two specimens of a taxonomically unrelated genus, Smenospongia (order Dicytoceratida). Considering the co-occur- 
rence of $\mathbf{5}$ with 5-bromo-L-tryptophan (1), one can speculate that $\mathbf{5}$ formed by cyclization of $\mathbf{1}$ followed by an oxidiation step to elaborate the $o$-quinonic structure.

\section{Acknowledgements}

This work was supported by NIH grant CA 36622 (C. M. I.). Funding for the Varian Unity
400 spectrometer was provided by NIH grant RR14768. We are indebted to Dr. Elliot Rachlin and Dr. Vajira Nanayakkara for recording mass spectra. We thank Dr. Bert Vogelstein for providing the isogenic HCT-116 cell lines. Special thanks are due to Pinar Akbay for the assistance at literature searches. Deniz Tasdemir appreciates the sabbatical leave given her by Hacettepe University.
Bano S., Ahmad V. U., Perveen S., Bano N., Shafiuddin and Shameel M. (1987), Marine natural compounds; II. Chemical constituents of red alga Botryocladia leptopoda. Planta Med. 53, 117-118.

Bernart M. and Gerwick W. H. (1990), 3-(Hydroxyacetyl)indole, a plant growth regulator from the oregon red alga Prionitis lanceolata. Phytochemistry 29, 3697-3698.

Bourguet-Kondracki M. L. and Guyot M. (1989), Biologically active quinone and hydroquinone sesquiterpenoids from the sponge Smenospongia sp.. Tetrahedron 45, 1995-2004.

Bourguet-Kondracki M. L., Martin M. T. and Guyot M. (1992), Smenoqualone, a novel sesquiterpenoid from the marine sponge Smenospongia sp.. Tetrahedron Lett. 33, 8079-8080.

Cannon J. R. and Williams, J. R. (1982), The alkaloids of Gastrolobium callistachys. Aust. J. Chem. 35, 14971500.

Casapullo A., Cutignano A., Bruno I., Bifulco G., Debitus C., Gomez-Paloma L. and Riccio R. (2001), Makaluvamine $\mathrm{P}$, a new cytotoxic pyrroloiminoquinone from Zyzzya cf. fuliginosa. J. Nat. Prod. 64, 13541356.

Cimino G., De Stefano S. and Minale L. (1972), Polyprenyl derivatives from the sponge Ircinia spinosula; 2Polyprenylbenzoquinones, 2-polyprenylbenzoquinols, prenylated furans and a C-31 difuranoterpene. Tetrahedron 28, 1315-1324.

Davidson B. S. (1993), Ascidians: producers of amino acid derived metabolites. Chem. Rev. 93, 1771-1791.

Djura P., Stierle D. B., Sullivan B., Faulkner D. J., Arnold E. and Clardy J. (1980), Some metabolites of the marine sponges Smenospongia aurea and Smenospongia (= Polyfibrospongia) echina. J. Org. Chem. 45, 14351441.

Engvild K. C. (1977), Preparation of chlorinated 3-indolylacetic acids. Acta Chem. Scand. Ser. B 31, 33383339.

Erdogan I. and Sener B. (2001), Two metabolites from the marine sponge Spongia officinalis L. Acta Pharm. Turc. 43, 17-19.
Ford J. and Capon R. J. (2000), Discorhabdin R: a new antibacterial pyrroloiminoquinone from two latrunculiid marine sponges, Latrunculia sp. and Negombata sp. J. Nat. Prod. 63, 1527-1528.

Gribble G. W. (1992), Naturally occuring organohalogen compounds - A survey. J. Nat. Prod. 55, 1353-1395.

Hu J.-F., Schetz J. A., Kelly M., Peng J.-N., Ang K. K. H., Flotow H., Leong, C. Y., Ng S. B., Buss A. D., Wilkins S. P. and Hamann M. T. (2002), New antiinfective and human 5-HT2 receptor binding natural and semisynthetic compounds from the jamaican sponge Smenospongia aurea. J. Nat. Prod. 65, 476-480.

Irie K., Ishida A., Nakamura T. and Oh-ishi T. (1984), Syntheses of substituted L- and D-tryptophans. Chem. Pharm. Bull. 32, 2126-2139.

Katekar G. F. and Geissler A. E. (1983), Structure-activity differences betweeen indoleacetic acid auxins on pea and wheat. Phytochemistry 22, 27-31.

Kinjo J., Matsumoto K., Inoue M., Takeshita T. and Nohara T. (1991), A new sapogenol and other constituents in Abri Semen, the seeds of Abrus precatorius L. I. Chem. Pharm. Bull. 39, 116-119.

Kitajima N., Watanabe S. and Takeda I. (1973), Bacterial production of L-tryptophan derivatives, patent to Asahi Chemical Industry Co., Ltd, Japan. Kokai 7398,091, 1973. CA 80, $106876 \mathrm{~g}$ (1974).

Kobayashi J., Cheng J., Ishibashi M., Nakamura H., Ohizumi Y., Hirata Y., Sasaki T., Lu H. and Clardy J. (1987), Prianosin A, a novel antileukemic alkaloid from the okinawan marine sponge Prianos melanos. Tetrahedron Lett. 28, 4939-4942.

Ma C.-M., Nakamura N. and Hattori M. (1998), Saponins and c-glycosyl flavones from the seeds of Abrus precatorius. Chem. Pharm. Bull. 46, 982-987.

McPail K., Davies-Coleman M. T. and Coetzee P. (1998), A new furanosesterterpene from the south african nudibranch Hypselodoris capensis and a dictyoceratida sponge. J. Nat. Prod. 61, 961-964.

Nakamura H., Deng S., Kobayashi J., Ohizumi Y. and Hirata Y. (1986), Dictyoceratin-A and B; antimicrobial terpenoids from the okinawan sponge, Hippospongia sp. Tetrahedron 42, 4197-4201. 
Narumiya S., Takai K., Tokuyama T., Noda Y., Ushiro H. and Hayaishi O. (1979), A new metabolic pathway of tryptophan initiated by tryptophan side chain oxidase. J. Biol. Chem. 254, 7007-7015.

Radisky D. C., Radisky E. S., Barrows L. R., Copp B. R., Kramer R. A. and Ireland C. M. (1993), Novel cytotoxic topoisomerase II inhibiting pyrroloiminoquinones from Fijian sponges of the genus Zyzzya. J. Am. Chem. Soc. 115, 1632-1638.

Rasmussen T., Jensen J., Christophersen C. and Nielsen P. H. (1993), Structure and synthesis of bromoindoles from the marine sponge Pseudosuberites hyalinus. J. Nat. Prod. 56, 1553-1558.

Rasmussen T., Christophersen C., Nielsen P. H. and Rajagopal R. (1995), Auxin activity of brominated indoles from the marine sponge Pseudosuberites hyalinus. J. Mar. Biotechnol. 2, 167-169.

Sakemi S., Sun H. H., Jefford C. W. and Bernardinelli G. (1989), Batzellines A, B, and C. Novel pyrroloquinoline alkaloids from the sponge Batzella sp. Tetrahedron Lett. 30, 2517-2520.

Schmidt E. W., Harper M. K. and Faulkner D. J. (1995), Makaluvamines $\mathrm{H}-\mathrm{M}$ and damirone $\mathrm{C}$ from the pohn peian sponge Zyzzya fuliginosa. J. Nat. Prod. 58, $1861-1867$.

Stierle D. B. and Faulkner D. J. (1991), Two new pyrroloquinoline alkaloids from the sponge Damiria sp. J. Nat. Prod. 54, 1131-1133.

Tasdemir D., Mangalindan G. C., Concepción G. P., Harper M. K. and Ireland C. M. (2001), 3,7-Dimethylguanine, A New Purine from a Philippine Sponge Zyzzya fuliginosa. Chem. Pharm. Bull. 49, 16281630.

Thymiak A. A., Rinehart K. L. Jr. and Bakus G. J. (1985), Constituents of morphologically similar sponges, Aplysina and Smenospongia species. Tetrahedron 41, 1039-1047.

Van Lear G. E., Morton G. O. and Fulmor W. (1973), New antibacterial bromoindole metabolites from the marine sponge Polyfibrospongia maynardii. Tetrahedron Lett. 299-300.

Venables D. A., Concepción G. P., Matsumoto S. S., Barrows L. R. and Ireland C. M. (1997), Makaluvamine $\mathrm{N}$ : A new pyrroloiminoquinone from Zyzzya fuliginosa. J. Nat. Prod. 60, 408-410. 